\title{
On Chinese Traditional Linguistics
}

\author{
Philology or Linguistics
}

\author{
Haiyan Li \\ School of Nationalities \\ Huanghe Science and Technology College \\ Zhengzhou, China
}

\begin{abstract}
For a long time, different people hold different view for whether Chinese traditional linguistics is philology or linguistics. This paper analyzes language research in various periods of China. It is mone practical that Chinese traditional linguistics belongs to philology. Meanwhile, it can be seen that Chinese traditional philology has laid a solid foundation for generation and development of Chinese linguistics.
\end{abstract}

\section{Keywords-linguistics; philology}

\section{INTRODUCTION}

With a long history, Chinese language research has begun to sprout as early as the Spring and Autumn Period and the Warring States Period, such as discussion on language issues by pre-Qin thinkers, debate on "name" and "actuality" in the Spring and Autumn Period and the Warring States Period, Shuo Wen Jie Zi written by Xushen from the Eastern Han Dynasty in the 1st century and Dialects written by Yang Xiong. However, there is dispute in whether Chinese traditional linguistics research belongs to philology or linguistics. Up to now, qualitative problems for it in academic circles are not unified, each airs his own views and no decision can be reached.

In the preface of History of Chinese Linguistics, Wang Li proposed that, "language research before the May Fourth Movement in Ch ina roughly belongs to philology range." He also proposed that, "before the Opium War, Chinese linguistics is basically philology; it even carries with nature of philology in research of dialects and slangs, because authors always make textual research on the sources of these dialects and slangs words. Philology has occupied a dominant position in Chinese language research for two thousand years."

Cen Qixiang proposed in A History of Linguistics, "Until the beginning of the 19th century, due to comparative study on various languages, life of language was gradually found and law of language development was organized and language research became scientific research."

In the preface of History of Ancient Chinese Linguistics, He Jiuying proposed that, "quite a bit of contents on research on Chinese phonetics or research on Chinese vocabulary the ancients belong to linguistics nature. Even today, we still put this nature research within the scope of linguistics." He also proposed that, "linguistics has been regarded as an independent subject since Han Dynasty."

$\mathrm{Pu}$ Zhizhen believes that ancient Chinese language research belongs to linguistics.

Then, ancient Chinese language research is on earth philology or linguistics? Which one is more practical? Through comprehensive opinions of scholars and combined with the author's experience, here, I talk about my immature views. I believe that, to determine nature of ancient Chinese language research, firstly we must clarify difference between linguistics and philology.

Linguistics is an independent science taking language as special research object, whose basic task is to research language law and make people understand conceptual knowledge of language. This research result can get scientific, systematic and comprehensive language theory. But philology is research on character or written language, whose purpose lies in checking and revising, textual research and interpretation of references. This research is mostly comparatively scattered, lacking systematicness and comprehensiveness and scientific insight.

Secondly, we should language research conditions in various periods in ancient China. We know that, there is a distinguished name in learning of ancient Chinese research on language and words, called "primary school." "Primary school" originally refers to the school where young children from eight years old to fourteen years old study. The ancients went to primary school from eight years old and the teacher taught them "the six categories of Chinese characters". Reading and writing was the main contents of teaching, therefore, later people called learning of reading and writing as "primary school". "Record of Art and Culture, History of Han Dynasty", "Ten primary schools include thirty five articles." "Primary school" has become a "school". Leaning on character research was called "primary school" since Han Dynasty (character research includes research on character pattern, meaning and pronunciation). Later, range of "primary school" was expanded, including character, phonology and exegesis.

Although debate on "name" and "actuality" in the Spring and Autumn Period and the Warring States Period involves nature of language and other issues, these philosophers and thinkers focuses on relationship between language and the 
world, the role of language in constructing ideal social politics and culture and do not discuss language itself. In Analects of Confucius Yen-Yuan, "Politics, justice. If you lead people to be just, who dare not to be just?" In Zuozhuan - Xuangong Twelfth Year, "Military forces are to be used only for the maintenance of peace and order." In Han Feizi · Five Academic Schools, "only thinking of oneself is selfish." They explain character meaning and character form so as to clarify certain philosophy or political view. For another example, in Zuozhuan . Zhuanggong Third Year, "Staying one night is She, two nights is Xin and the next night is Ci", in Wen Gong Seventh Year, "The soldiers fighting in home country cause chaos and the soldiers fighting against other country are enemy." In Laozi, "Because the eye gazes but can catch no glimpse of it, it is called elusive. Because the ear listens but cannot hear it, it is called the rarefied. Because the hand feels for it but cannot find it, it is called the infinitesimal." They explain character meaning so as to illustrate certain term of military and philosophy. Also, in Zuozhuan - Wengong Seventh Year, 〈Book of Odes. Psalms Major. Ban〉 'although we do different job, we are colleagues'. Xun Linfu explained it as "the officials are colleagues", in Mencius. King Hui of Liang II, "movement 〈Weizhao〉 〈Jiaozhao〉, 'to correct the monarch's loss, why is it a fault, Mencius explained, 'to correct the monarch's loss is love the monarch"”. They explained character meaning so as to interpret the quoted ancient books. Meanwhile, some grammar issues were involved inevitably, for example, in Spring and Autumn Annals · Zhuanggong Tenth Year, "Song State people migrated to Su State." Gongyang Commentary: "Why do the people migrate? Non-open, the land is taken to recover it." Spring and Autumn Annals · Huangong Eighth Year, "Jigong came and then married the queen in Ji." Biography of Guliang, "Sui refers to the word of do next thing." In Spring and Autumn Annals · Xigong Forth Year, "in winter, Gong crusaded against Zheng State." In Biography of Guliang, "Why? The battle is caused by the non-compliance of rescue promise, Gong crusaded against Zheng State." These phenomena are confined to paraphrase some words and phrases hard to understand or with doubt, but are not to be identified from grammar, so they are comparatively scattered and non-systematic research.

Language develops along with social development. In Han Dynasty, the age is far, character pronunciation, pattern and meaning changes. The phenomenon that "the speech has different pronunciations and the character has different patterns" appears. Due to difference between current language and ancient language, it is not easy for people to understand classical literature, therefore, different language and dialects in various places should be explained. In Qin and Han Dynasties, research on language and words focuses on collection and sort of words and explanation of word meaning. As the earliest exegesis monograph to generally explain various classics, Er Ya can solve many problems in Confucian classics and become the most tool of reading classics and mastering classics in Han Dynasty because it mainly collect and interpret Confucian classics. Simulating style of Er Ya, and collecting the words and expressions with the same meaning in all places in ancient and modern times,
Dialects mainly makes subsequent people know their original conditions, and explain the dialects. One paragraph in Dialects can be seen the purpose of writing dialects by Yang Xiong. "Ancient and modern language refers to language originally spoken by different countries not contacting with each other. The same with today, ancient books and documents of official history and ancient saying words do not loss their methods, while the descendants do not know them, therefore, commentary notes are made. "In Eastern Han Dynasty, far away from ancient times, the ancient books are more and more intricate and obscure, it is difficult to pronounce or comprehend the diction. Xu Shen's Shuo Wen Jie $\mathrm{Zi}$ is just generated complying with the times requirements. Interpreting pattern, explaining meaning and distinguishing pronunciation quotes quite a few materials of ancient Chinese classics, and help people to understand classics. The Book of Title Explanation written by Liu $\mathrm{Xi}$ is the first book of Chinese etymology. It attempts to explain meaning from sound, and study the origin of name. He stated the purpose of writing this book in preface. "For name and actuality, there are various meaning categories. The masses call things but do not know their meanings. So heaven and earth, Yin and Yang, the four seasons, country state, fiefs, carriages and clothes and funeral arrangements, lower to instruments applied by ordinary people are discussed and classified, called the Book of Title Explanation." Works in this period, except that Dialects records some living language, paraphrase of most works are still confined to ancient books, the purpose is not to research language, but to solve problems in learning classical literature and read classics, with very strong practicability.

Language research in Wei and Jin dynasties mainly focuses on character and exegesis. The purpose of writing Guangya by Zhang Yi is to widen $\operatorname{Er} Y a$, Zhang Yi proposed in Shangguangyabiao, "Er $\mathrm{Ya}$, a book contains simple te xts and solid meaning; the principles stated in it are accurate and error free, detection of true seven classics, steps of learning and model of the scholars' circle. Even if it includes heaven and earth, guiding principles and human events, power system, it cannot be perfect for exegesis by various families. I record and examine the knowledge, same text with different meanings, the pronunciation loss due to transfer, special speech in all directions, all things renamed not include in $\operatorname{Er~Ya}$ so as to write this book. "Zilin written by Lv Chen is to supplement incomplete explanation of Shuo Wen. In this period, influenced by metaphysic and Buddhism, due to obscure commentaries notes and words and unknown literary content in previous generation, the readers still feel difficult to understand classics through Shuo Wen. Therefore, the authors who made notes have to make notes for classics as well as commentaries notes to facilitate people to learn. For example, Collation of Commentary and Subcommentary to the Thirteen Classics are mostly notes made by people in Han Dynasty or Wei and Jin dynasties.

Language research from the Northern and Southern Dynasties to Yuan and Ming Dynasties focuses on research on ancient pronunciation. In the late Han Dynasty, fanqie formula generated under the influence of alphabetic writing of Buddhist texts, is originally used for phonetic notation of 
classics, and it prevails in Qi and Liang Dynasties. The Annotation of Classics written by Lu Deming from Tang Dynasty do not only make phonetic notation for classics, but also analyze the meaning of classics and annotations. In addition, in the Northern and Southern Dynasties, Chinese literature particularly pursues form stresses ornate phraseology and stresses rhythm; in Tang Dynasty, development of metrical poetry, classical Chinese poem, poetic essay entered perfect artistic state. These cultural characteristics have played a role of promoting language research in this period. With a good understanding in melody and influenced by Buddhism, the literature scholars discovered "four tones", which served for meter of five characters poetry originally. Appearance of fanqie formula and discovery of four tones, and requirements of literature generated many rime dictionaries, such as Qie Yun, Wuyin Jiyun, Guangyun, Jiyun, Central China Phonology, Hongwu Zheng Yun and so on. Rime dictionaries are generated to adapt to requirements of poetry and prose. In Yun Xue Yuan Liu, Mo Youzhi proposed, "The rime today is the rhythm followed by poets in past dynasties from Sui and Tang dynasties." In the preface of Qie Yun, Lu Fayan proposed, "To widen literature path, you can have a good knowledge of sonorant and non-sonorant, to enjoy pronunciation, you should differ stress from light tone." Also said, "Any decorative embellishment of writing need clear phonology." The purpose of Qie Yun is to distinguish pronunciation, correct pronunciation and adopt rhyme for poems. Guangyun refers to Dasong Chongxiu Guangyun, with the meaning of Guangqiexun, it is the first officially compiled rime dictionary in our country, also can be taken as a dictionary arranged in rhyme. Central China Phonology makes complete reformation for traditional rime dictionaries, it basically reflects pronunciation condition in Dadu of Yuan Dynasty, but complied for composition. Zhou Deqing states clearly in Preface, "To write the collection of folk songs and ballads, you must specify speech; to specify speech, you must follow Central China phonology. Prosperity, perfection and difficulty of folk songs and ballads exist now particularly. Prosperity means that from officials and common people, they sang the collection of folk songs and ballads. Perfection means that once works of Guan Hanqing, Zheng Guangzu, Bai Pu, Ma Zhiyuan, the rhymes follow natural sound and the characters are connected with language in the world" "Study on Alphabets" appeared in Tang and Song Dynasties, followed by "Study on Dengyun", the purpose is to help people correctly spell out pronunciation of characters and correctly understand meaning of classic works. Because pronunciation changed, people in Six Dynasties would temporarily change these pronunciations so as to reach harmonious rhyme when they feel the pre-Qin verses such as The Book of Songs and The Songs of Chu were not rhymed and harmonious through "Ye Tone" and "Xie Rhyme". In Song Dynasty, some people explained rhyme of The Book of Songs comprehensively through "Ye Tone". This is wrong, they did not realize that language was developing, and pronunciations in ancient and modern times were not different. Chen $\mathrm{Di}$, an old Chinese phonology scholar in Ming Dynasty, wrote The Textual Research for Ancient Pronunciation in the Book of Songs Annotated by
Mao, and proposed the correct viewpoint of "there are ancient and modern times, the land is in the north or south, the character is changing and the pronunciation is transferring, which is the trend". Research on phonology had gotten the substantial development since Han-Wei period; some comparatively scientific achievements were also obtained, with linguistics. But the research still serves to explain classics and compose poems, but not proceeds from linguistics angle.

In Qing Dynasty, the governors strictly controlled cultural thoughts, the scholars were engaged in arrangement and textual research of ancient books in order to avoid the reality and "down-to-earth learning" was formed. Character, phonology, exegesis in this period was developed comprehensively and remarkable achievement was obtained, and character, phonology, exegesis was most glory in Qianlong and Jiaqing period. Philology mainly explains characters, for example, Duan Yucai, Zhu Junsheng, Gui Fu and Wang Jun researched on explanation of characters, but they mostly made textual criticisms and explanations and correction; phonology mainly researches ancient phonology, for example, Gu Yanwu, Jiang Yong, Dai Zhen, Duan Yucai, Kong Guangsen, Wang Niankong, Jiang Yougao, Zhang Binglin and Huang Kan respectively divided archaic Chinese rhyme, in initial consonant, Qian Daxi proved " there are no labial sound and tip-tongued affricates in ancient times." "The purpose of phonology research is to read classics, as $\mathrm{Gu}$ Yanwu said, "naturally, six Confucian classics can be read. There is separation and reunion in books written by other scholars, not very far"; Exegetics mainly researches interpretation of ancient meaning, for example, Wang Niansun's Guang Ya Shu Zheng, Du Shu Za Zhi, Wang Yinzhi's Jin Yi Shu Wen, Word Meaning of Classics made textual criticisms and explanations by old Chinese phonology to seek ancient meaning so as to better read ancient books. Also, Shao Jinhan's Eryazhengyi, Hao Yixing's Eryayishu, Dai Zhen's Brief Textual Criticism on Dialects, Yu Yue's Ordinance of the Cite from Old Works of Doubtful Point, Zhang Binglin's Guo Gu Lun Heng made annotation, textual criticism, arrangement for ancient books, with the fundamental intention of serving study of Confucian classics. Although great achievements are made in language research in Qing Dynasty, but the range is confined to before Han-Wei period, and confined by classic works, "books not written in Pre-Qin and Han Dynasties cannot be read". Language research is stills attached to study of Confucian works and serves study of Confucian works.

Although research on grammar existed long ago and the noun of "function words" appeared, "notional words" and "function words" appeared after Song Dynasty, and there were not a few works in Ming and Qing Dynasties, such as Yuan Renlin's On Functional Words, Liu Qi's Zhu Zi Bian Lue, Wang Yinzhi's Jing Zhuan Shi Ci. However, generally, the purpose of works is to make certain proofreading and comments on words and phrases hard to understand or with doubt in Confucian classics or ancient books, but they cannot become complete and systematic research. Until appearance of Ma Shi Wen Tong, there are systematic grammar works in China. 
Through a general survey, ancient Chinese language research is subordinate position and not developed into independent subjects, mostly with the following general characteristics: firstly, from research purpose, it generally explains classics, helps people to read literature classics at that time, does not research language for language; secondly, from research object, most of research is research on written language or characters; thirdly, from research method, most research lacks systematicness, comprehensiveness and scientificity. Development of language research is determined by history of social development and characteristics of Chinese characters. China is feudal society for a long time, all the governors worship former emperors doctrine and respect classic works and ancient books, and select talents in this way, therefore, all research is made for people to understand classics and attain practical use; moreover, Chinese characters are ideograph, combination of pronunciation, pattern and meaning. To learn to read characters and classics, we should understand structure of character pattern, know character pronunciation and be aware of character meaning, otherwise, we cannot read Confucian classics.

Ancient Chinese language research explains certain specific language facts. All language research is to implement special processing of concrete issues, with the purpose of practicability, that is, understand classics". Therefore, it will not make systematic ontology research on the whole language.

From analysis above, philology is more practical to ancient Chinese language research. But we cannot deny linguistics composition, philology breeds linguistics and provides many materials for linguistics, for example, research on Chinese characters in Han Dynasty, phonology research after the Wei and Jin dynasties and so on actual contains linguistics composition and lays a solid foundation on generation and development of linguistics. As Lu Zongza and Wang Ning said, "Chinese work and language research are originally condensed together, cannot be separated from each other like water and emulsion; if you insist on separating them, you will go into dead end inevitably. "We should dialectically consider ancient Chinese linguistics when learning and researching language. Just this philology with practical purpose promotes development of linguistics, plus influence of western learning introduced into China, it promotes people to further explore various laws based on individual language research results. Especially after "May Fourth" Movement, the linguists have more sober scientific mind, understand to analyzes issues scientifically, emphasize research on Vernacular Chinese and comprehensively starts research on linguistics, so far, language research in our country has taken an independent development path.

\section{REFERENCES}

[1] Wang Li. History of Chinese Linguistics[M]. Shanxi People's Publishing House. 1981

[2] Cen Qixiang. A History of Linguistics [M]. Science Press. 1958

[3] He Jiuying. History of Ancient Chinese Linguistics [M]. Henan People'sPublishing House 1985
[4] Pu Zhizhen. History of Chinese Linguistics[M]. Shanghai Classics Publishing House. 1987

[5] Ye Feisheng, Xu Tongqiang. Linguistics Summary[M]. Pecking University Press. 1981

[6] Jin Shuhua. Review on Debate between Philology and Linguistics Journal of Sichuan University of Arts and Science 2001 